physical fitness and to decrease or to stop cigarette smoking; both of these are associated with an increased sense of wellbeing and the latter decreases the incidence of -other serious diseases. Decreased sugar and fat intake, anticoagulant treatment, rigid control of hypertension, drugs to lower blood cholesterol levels, oestrogen therapy, and other possible panaceas for the scourge of coronary disease do not have the same attractions, since none is associated with any subjective feelings of improvement; weight loss, however, can lead to a remarkable improvement in morale in the few who are able to achieve dramatic results.

The practising doctor can take one of two possible attitudes towards the somewhat inconclusive benefits of weight reduction, and either can be applied to his patients in general or to those with known coronary disease in particular. He may argue that coronary disease is the most common single cause of death and that any treatment which may be beneficial and which is not definitely harmful can sensibly be advocated. Weight reduction certainly meets these criteria, and a doctor might reasonably consider it right to hound his patients into strenuous attempts at weight reduction. Experienced physicians will appreciate the low incidence of success which is likely to be achieved, but they may feel that even this justifies the discomfort of the unsuccessful majority who often go hungry to no avail. The other attitude, the opposite extreme, is to regard the results to date with scepticism, particularly as they apply to persons without overt evidence of coronary disease. Advice to take more excercise and avoid putting on further weight may be all that can be recommended with any confidence to normal subjects and even to those with known coronary disease. In general, weight reduction by reduced food intake seems sound advice when given to those who appear to have the personality and ability to achieve it; it can be coupled with advice to take more exercise, but exercise alone without dietary restriction is unlikely to lead to any diminution in weight. Exercise might, however, be more effective in reducing the incidence of coronary disease; but this like many other questions remains to be solved.

1 Keys, A., et al., Annals of Internal Medicine, 1972, 77, 15.
2 Ashley, F. W., Jnr., and Kannel, W. B., fournal of Chronic Diseases, 1974, $27,103$.

${ }^{3}$ Lewis, B., et al., British Medical fournal, 1974, 3, 489.

4 Carlson, L. A., and Böttiger, L. E., Lancet, 1972, 1, 865.

\section{Surgery for Hyperlipidaemia}

Both hypercholesterolaemia ${ }^{1-4}$ and hypertriglyceridaemia ${ }^{4}$ are associated with an increased risk of developing clinical coronary heart disease, and treatment is generally recommended in the hope that the underlying artherosclerotic process may be concomitantly reduced. Conventional therapy for hyperlipidaemia usually starts with modification to the diet, with the later addition of one or more lipid-lowering drugs if the response to diet alone proves inadequate. ${ }^{6}$ Some patients with severe hyperlipidaemia fail to respond adequately to such treatment, however, or find the dietary changes required difficult to maintain over long periods of time; so there is occasionally a need for an alternative form of therapy.

The operation of partial ileal bypass has received increasing attention in recent years. The ileum is divided $200 \mathrm{~cm}$ from the ileocaecal valve, and an end-to-side ileocaecostomy constructed, the upper end of the distal bowel being closed. ${ }^{7}$ The procedure is thus considerably less extensive than that of jejuno-ileal bypass for the treatment of intractable obesity. ${ }^{8}$ The twofold rationale of the operation is reduction in the absorption of cholesterol by the small intestine and prevention of the reabsorption of bile acids which normally occurs in the terminal ileum, thereby interrupting their enterohepatic recirculation and increasing the catabolism of cholesterol to bile acids within the liver by the removal of negative feedback. ${ }^{9}$ Though these effects are accompanied by an increase in hepatic cholesterol synthesis, the net result is usually a substantial fall in the plasma cholesterol concentration.

The operation has been extensively employed by Buchwald et al. at the University of Minnesota, and they have recently reviewed ${ }^{7}$ their experience with more than 100 cases treated over the past 10 years. Average reductions in plasma cholesterol concentration of $40 \%$ (range 5-79\%) have been achieved, with $80 \%$ of the subjects having reductions in excess of $25 \%$. This effect was observed in patients with all types of primary endogenous hyperlipoproteinaemia (types IIa, IIb, III, and IV). In several patients the fall in cholesterol concentration was accompanied by a decrease in the size of cholesterol xanthomata, ${ }^{10}{ }^{11}$ while in studies carried out on three patients the total body-pool of exchangeable cholesterol appeared to decrease by an average of $35 \%$ during the first year after surgery. In those patients with hypertriglyceridaemia ileal bypass surgery also reduced the plasma concentration of triglyceride, though in those with hypercholesterolaemia alone small increases in plasma triglycerides have occurred. The operation appears to be safe, and so far no deaths attributable to the surgical procedure have occurred. Postoperative morbidity has been confined to three cases of small bowel obstruction due to the formation of adhesive bands. In contrast to the jejuno-ileal bypass operation for obesity, body weights have generally remained unchanged after surgery, and there has been no incidence of impaired liver function or of electrolyte imbalance; children have maintained a normal growth curve. Though an increased frequency of bowel habit has been usual after surgery it is apparently seldom that this has been persistent or troublesome; nor have there been problems with steatorrhoea. However, the absorption of vitamin $B_{12}$ is impaired postoperatively and parenteral supplementation is necessary.

Partial ileal bypass for the treatment of hyperlipidaemia has been less extensively studied outside Minnesota, but the more limited experience of other investigators appears to be similar. ${ }^{11-13}$ The operation seems, therefore, to offer a relatively safe and effective means of lowering plasma lipid concentrations in patients who cannot be adequately treated by more conventional methods. As with other forms of lipidlowering therapy, however, its effect on the development of ischaemic heart disease has yet to be established, and the results of long-term prophylactic trials will be required before its real value can be assessed. In the meantime, the survival $^{7}$ in Minnesota of $75 \%$ of patients with pre-existing clinical coronary heart disease for 5 or more years after surgery is at least encouraging. Reports that animals in which the operation has been carried out showed evidence of regression of atherosclerosis have also provided a cause for some optimism. ${ }^{14} 15$

\footnotetext{
1 Kannel, W. B., et al., Annals of Internal Medicine, 1971, 74, 1.

2 Doyle, J. T., et al., American fournal of Public Health, 1957, 47, 25. Public Health, 1957, 47, 33. Albrink, M. J., and Man, E. B., Archives of Internal Medicine, 1959, 103,4 .

5 Carlson, L. A., and Bottiger, L. E., Lancet, 1972, 1, 865

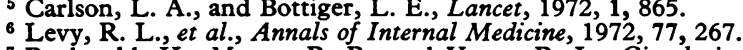

7 Buchwald, H., Moore, R. B., and Varco, R. L., Circulation, 1974, 49, suppl. 1 .
} 
8 Weismann, R. E., American fournal of Surgery, 1973, 125, 437.

Boyd, S.G., and Percy-Robb, I. W., American Fournal of Medicine, 1971, $51,580$.

10 Buchwald, H., Fournal of Artherosclerosis Research, 1969, 10, 1.

1 Helsingen, N., and Rootwelt, K., Nordisk Medicin, 1969, 82, 1409.

12 Swan, D. M., and McGowan. J. M., American Fournal of Surgery, 1968, 116, 22.

${ }^{13}$ Sodal, G., Gjertsen, K. T., and Schrumpf, A., Acta Chirurgica Scandinavica, 1970, 136, 671.

14 Scott, H. W., et al., Annals of Surgery, 1966, 163, 795.

15 Shepard, G. H., et al., Surgical Forum, 1968, 19, 302.

\section{Lightning}

Nearly 50,000 thunderstorms occur each day throughout the world, with results varying from the fixation of nitrogen in the atmosphere to starting forest fires, interfering with the overhead distribution of electricity, damaging property, and occasionally killing animals and people. About 12 people a year are struck by lightning in Britain; the corresponding figure for the U.S.A. is 150 . Among the six million inhabitants of Rhodesia, however, there are on average 60 deaths from lightning each year. Analysis of these figures ${ }^{1}$ shows a preponderance of victims among rural Africans, and a regional variation with more deaths in the areas where "dry" thunderstorms are more common, the suggested explanation being that cloud-to-ground lightning strokes are more likely to be encountered in these conditions.

The mechanism of the lightning storm is complex and probably not fully understood. Traditionally thunder and lightning are linked to a change in weather characterized by wind, a fall in temperature, dark cloud formation, and rain. Less frequently lightning can occur on a clear day-the "bolt from the blue." In similar fashion the discharge itself may vary in type and may be from cloud to cloud or between cloud and ground. The lightning stroke is not a simple spark but a more complex discharge, with different constituent parts. First a leader forms a path from cloud to earth (or occasionally the reverse). This is then followed by the main return stroke, discharging along the same path in the opposite direction, with as many as 40 successive current peaks varying from $10,000-200,000$ amps occurring in the space of a fraction of a second, and with a potential difference of up to 20 million volts.

Tall structures may initiate upward leaders, and for that reason people caught in a storm are advised not to shelter under trees and to avoid flat open areas such as golf courses, where they may form the highest point. Shelter indoors is safer than being outside, while anyone unable to take refuge in a building should avoid metal structures such as fences, sheds, park seats, and tentpoles.

The post-mortem findings associated with lightning strike ${ }^{2}$ include damage to clothing and skin, fractured bones, burns, and magnetization of metallic articles worn or carried by the victim. Both the burns and respiratory and cardiac arrest may result from passage of electricity through the body, while the evidence of physical violence is related to the thermal effect of the discharge through the air.

Survival after lightning strike is sufficiently dramatic to be reported in the popular press: recovery may be spontaneous ${ }^{3}$ or may follow resuscitation. The victim of a lightning strike does not harbour any remaining electric charge and so can be approached safely. Cardiorespiratory arrest may respond to external cardiac massage and ventilation, and both should be continued for some time-Ravitch et al. ${ }^{4}$ and Nesmith ${ }^{5}$ agree that these patients may be able to withstand apnoea for prolonged periods; indeed Taussig ${ }^{6}$ has suggested that the electrical effect of lightning strike halts cellular metabolism and delays the effect of anoxia.

Cerebral oedema may develop fairly rapidly after electrocution, so steps such as the administration of mannitol should be taken. Generalized paralysis has also been described, though it is rarely permanent unless secondary to such effects as cerebral hypoxia. Hanson and McIlwraith ${ }^{7}$ described gastrointestinal dilation as a complication and they suggested passing a gastric tube, which should also reduce the risk of pulmonary aspiration. They also warned that the blast effects of the discharge could cause contusion of the lung, intestine, and myocardium as further complications.

Lightning may in fact strike in the same place twice, but is unlikely to strike in the same doctor's experience more than once. The single most important feature of lightning injury is the delay in signs of response to resuscitation, and the rule should be that external cardiac massage and ventilation should be continued at least until the patient's arrival at hospital.

\footnotetext{
${ }^{1}$ Castle, W. M., and Kreft, J., Central African Fournal of Medicine, 1974, 20, 93.

Simpson, K., Forensic Medicine, 4th edn. London, Edward Arnold, 1961. 3 Sunday Express, 18 August 1974

4 Ravitch, M., et al., New England fournal of Medicine, 1961, 264, 36.

5 Nesmith, M., Fournal of the Florida Medical Association, 1971, 58, 36.

6 Taussig, H., Annals of Internal Medicine, 1968, 68, 1345.

7 Hanson, G., and McIlwraith, G., British Medical fournal, 1973, 4, 271
}

\section{Intrauterine Chemical Release}

The pill and I.U.D. are firmly established as alternative and complementary forms of conception control. The frequency of undesirable side effects and lower efficacy of the inert, "first-generation" types of device have, however, prompted a search for improved design and led to the development of active, "second-generation" I.U.D.s. These are, in effect, local systems for the release of specific contraceptive agents into the uterine cavity.

Devices depending on the release of metallic copper, such as the $\mathrm{Cu}-\mathrm{T}$ and $\mathrm{Cu}-7$, are perhaps the most familiar of these new types of I.U.D. Zipper et al..$^{1-3}$ showed that copper (and certain other metals such as zinc) attached to an intrauterine carrier can markedly enhance its contraceptive efficacy in both experimental animals and women. The clinical performance of the latest models of copper I.U.D.s such as the Gravigard is very encouraging. While the rate of unintended pregnancy associated with their use is higher than that with the combined pill, it is much the same as with sequential and progestogen-only types of oral contraceptive, while their rates of expulsion, medical removal, and continuation are generally superior to those of the inert devices. Copper I.U.D.s can also be inserted more easily than conventional ones in multiparous women and in those with a narrow or distorted cervix. These general impressions may need modification, however: a recent British trial of 2,000 fittings of the Gravigard device has yielded a cumulative pregnancy rate substantially higher than that recorded in earlier, small-scale studies. ${ }^{4}$

The precise mode of action of the copper devices is still far from clear, but there may be several mechanisms. The prevail- 